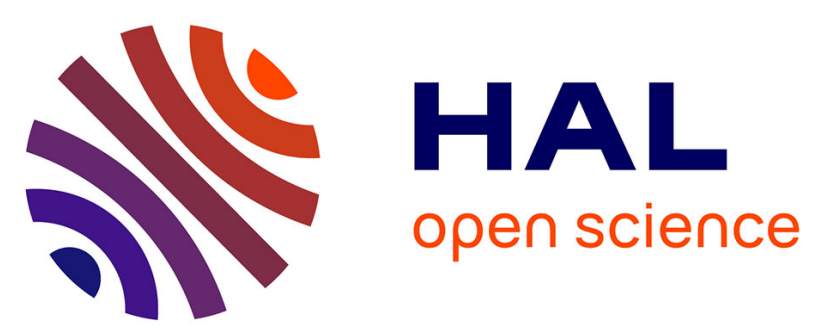

\title{
Simple and Versatile Analytical Method for Monitoring the Deposition of Thin Layers by Optical Measurement and Calculation of Residual Stress
}

\author{
Quentin Hatte, Mireille Richard-Plouet, Pierre-Yves Jouan, Pascal Casari, \\ Pierre-Antoine Dubos
}

\section{To cite this version:}

Quentin Hatte, Mireille Richard-Plouet, Pierre-Yves Jouan, Pascal Casari, Pierre-Antoine Dubos. Simple and Versatile Analytical Method for Monitoring the Deposition of Thin Layers by Optical Measurement and Calculation of Residual Stress. Thin Solid Films, 2021, 725, pp.138635. 10.1016/j.tsf.2021.138635 . hal-03266234

\section{HAL Id: hal-03266234 \\ https://hal.science/hal-03266234}

Submitted on 12 Jul 2021

HAL is a multi-disciplinary open access archive for the deposit and dissemination of scientific research documents, whether they are published or not. The documents may come from teaching and research institutions in France or abroad, or from public or private research centers.
L'archive ouverte pluridisciplinaire HAL, est destinée au dépôt et à la diffusion de documents scientifiques de niveau recherche, publiés ou non, émanant des établissements d'enseignement et de recherche français ou étrangers, des laboratoires publics ou privés. 


\section{Highlights:}

- A simple analytical method has been developed to characterize residual stress.

- The analytical method is versatile and suitable for thick, thin, mono or multilayers.

- The method was successfully applied to coatings deposited by Physical Vapour Deposition involving a High Power Impulsed Magnetron Sputtering and sol-gel.

- Coatings studied are interesting for anticorrosion applications.

- Links were made between residual stress and the structure of the coatings. 


\section{Simple and Versatile Analytical Method for Monitoring 2 the Deposition of Thin Layers by Optical Measurement 3 and Calculation of Residual Stress}

Quentin Hatte ${ }^{\mathrm{a}, \mathrm{b}}$, Mireille Richard-Plouet ${ }^{\mathrm{b}}$, Pierre-Yves Jouan ${ }^{\mathrm{b}}$, Pascal Casari ${ }^{\mathrm{a}}$, Pierre-Antoine Dubos* ${ }^{\text {a* }}$

${ }^{\text {a }}$ Institut de recherche en génie civil et mécanique, GeM Université de Nantes, UMR6183, IUT de Saint-Nazaire, 58 rue Michel Ange, BP 420, 44606 Saint-Nazaire, Cedex, France

${ }^{\mathrm{b}}$ Université de Nantes, CNRS, Institut des Matériaux Jean Rouxel, IMN, F 44000 Nantes, France

*Corresponding author

E-mail address: pierre-antoine.dubos@univ-nantes.fr

\section{Abstract}

This paper develops a simple and versatile analytical method for characterizing residual stress associated with the deposition of thick, thin, single and multilayer coatings. This study is of great importance, since the generation of residual stress can lead to the formation of significant defects in the coating. To illustrate the effectiveness of our analytical method, two different processes were characterized. The coatings formed are intended for anti-corrosion applications. The first is a Physical Vapour Deposition (PVD) involving a High Power Impulsed Magnetron Sputtering, the second is a sol-gel process. The approach is based on the optical recording of the curvature of a thin substrate, followed by its assessment using a fit of the digitalized image by a parametric model. The results provide experimental data on the development of stress during deposition. Both coatings studied have a low level of residual stress, which explains why they are flawless and which is interesting for the targeted anticorrosion application. For the PVD coating, it was possible to link the development of the stress to the evolution of the film structure during growth. For the sol-gel process, the study of the 
1 stress allowed us to highlight the drying reaction mechanisms involved during the sol-gel

2 transition and their influence on the gel structure.

4 Keywords: Residual stress, Multilayer-coating, Physical Vapor Deposition; High Power Impulsed Magnetron Sputtering, Sol-gel, Process monitoring, 


\section{Introduction:}

2

The development of residual stress related to thin film deposition is widely documented in literature. Such stress depends on many variables related to the process and materials used. In some cases, they may reach the tensile strength of the bulk material [1]. Studying the transient mechanical state of samples during manufacturing often explains the origin of a certain number of defects such as buckling, delamination [2] or cracking [3]. It is also possible to characterize the residual stress level of the interface within a multilayer system [4] or explain, with mechanical consideration, the evolution of the coating microstructure $[5,6]$. Depending on the applications, several approaches were proposed to characterize the magnitude of stress level.

$\mathrm{X}$-ray diffraction is an effective method for quantifying the level of residual stress in only crystalline materials [7]. This approach is based on the use of inter-reticular distance as a strain gauge and on the shift of the diffraction peak of a chosen plane when it is affected by stress. However, this method is dependent on the penetration of X-rays into the material, which can complicate the analysis of thick and multilayer films.

The equation introduced by Stoney [8] is also often used. In this case, the measurement is based on determining the radius of curvature of a sample before and after the deposition. This model requires several hypotheses, not always fulfilled in the literature: the thickness of the deposited layer is required to be much smaller than that of the substrate, the substrate and the coating are both homogeneous and isotropic, the curvature resulting from the stress is uniform, the longitudinal dimensions of the system (layer(s) and substrate) are much greater than its thickness. If these requirements are met, we can calculate the average stress in the layer thus (equation ((1)): 


$$
\sigma_{f}=\frac{E_{s} t_{s}{ }^{2}}{\left(1-v_{s}\right) 6 t_{f}} \times\left(\frac{1}{R_{1}}-\frac{1}{R_{0}}\right)
$$

With $\sigma_{f}$ the average stress in the layer, $E_{s}$ and $v_{s}$ respectively the Young's modulus and Poisson's ratio of the substrate, $t_{s}$ and $t_{f}$ the thicknesses of the substrate and the layer, and $R_{l}$ and $R_{0}$ the curvature radii of the sample measured experimentally after and before the deposition. This method does not enable the estimation of the stress profile through the thickness of the coating. However, this information can be important. In fact, a slightly curved sample will have a low average residual stress, but this can be linked to two contributions that counterbalance each other: one in traction and the other in compression. The non-homogeneity of coatings along the thickness has been reported for example in Djouadi et al. [9]. In this study, the dynamic stress profile during the deposition of boron nitride films was performed. Results showed an increase in stress in the first hexagonal layer, followed by a stress relaxation as the cubic phase appeared.

These two methods are the most widely reported, although other techniques have been developed in order to overcome some limitations. For example, the incremental hole-drilling or layer-by-layer ion erosion methods can be used to plot the stress profile in the thickness of the coating [10]. Another, more direct method is the use of grazing incidence X-rays diffraction [11], but this technique is not suitable for amorphous materials. Finally, when the measurement of the radius of curvature cannot be performed and the use of a destructive method poses no problem, indentation of the coating may be a solution [12]. This indirect method still requires an analytical model. However, none of these conventionally used methods makes it possible to retrieve or to extract the stress profile in multilayer coatings, deposited on thick substrate.

In this article, a simple and versatile analytical method suitable for thin $(<1 \mu \mathrm{m})$ or thick film and multilayer or monolayer coating was carried out to characterize the stress occurring in a film prepared by a Physical Vapor Deposition (PVD) and a chemical process (sol-gel). These 
1 coatings aim to be used as surface treatment of steel before the application of anti-corrosion

2 paint. They are intended to increase the barrier effect, on the one hand, and to improve the

3 adhesion of the paint film, on the other hand. The final goal of these treatments is to increase

4 the durability of the entire system in order to limit the maintenance phases. A precise 5 characterization of these surface treatments is necessary to assess their relevance. As explained 6 above, stress plays a key role in the coating durability. Since stress is mainly developed during 7 the manufacturing stage, this study focused on the evolution of stress during the process. Stoney or XRD methods are not relevant to assess stress in these films because the PVD coating is multilayered, the gel is thick and not crystallized respectively. Therefore, we developed an alternative method based on the assessment of curvature and its modeling through an analytical method.

Thus, using an optical measurement of the sample curvature, an analytical model was developed to assess the stress field induced in each layer. It is based on the prediction of residual thermal stress level in multilayer coating systems [13]. Here we propose to introduce in the analytical model a fictive (numerical) temperature difference to have access to the residual stress. By implementing this analytical method, we could establish that the incorporation of an intermediate layer limited the interface residual stress and therefore the interface loading [4]. In this study, this analytical method was applied to assess the evolution of residual stress occurring during High-Power Impulse Magnetron Sputtering (HiPIMS) and sol-gel processes. The validity and quality of the results are discussed with the literature and previous results based on other characterization techniques [14]. This provides experimental data on the development of stress related to sol-gel and HiPIMS deposition processes. 


\section{Method:}

2

3

4

5

6

7

\subsection{Deposition of coatings}

\subsubsection{Substrate Preparation}

Low carbon cold-rolled steel sheets $(30 \mu \mathrm{m}$ thick) were cut to produce rectangular substrates: $20 \mathrm{~mm}$ long and $2 \mathrm{~mm}$ wide. This geometry was chosen to get a measurable curvature due to stress development. The sample must be sufficiently thin and long enough to have a measurable (sufficiently large) curvature. A strip-shaped geometry (smaller width than length) leads to unidirectional curvature. This curvature is large enough to be evaluated by stereomicrography. Substrates were cleaned in an ultrasonic bath for $10 \mathrm{~min}$ in ethanol before PVD process to remove organic species. For the sol-gel process, they were cleaned with a dilute phosphoric acid solution, rinsed with warm water $\left(60^{\circ} \mathrm{C}\right)$ and dried with compressed air.

\subsubsection{Nickel and Nickel Oxide Deposition}

Table 1: Deposition parameters for the PVD process in High-Power Impulse Magnetron Sputtering (HiPIMS) mode.

\begin{tabular}{|l|l|l|l|}
\hline Step No. & 1 & 2 & 3 \\
\hline Material & $\mathrm{Ni}$ & $\mathrm{Ni}$ & $\mathrm{NiO}$ \\
\hline Step duration & $20 \mathrm{~min}$ & $20 \mathrm{~min}$ & $20 \mathrm{~min}$ \\
\hline
\end{tabular}

\begin{tabular}{|c|c|c|}
\hline \multicolumn{2}{|c|}{ Substrate to target distance } & $80 \mathrm{~mm}$ \\
\hline \multicolumn{2}{|c|}{ Diameter / thickness of the target } & $75 / 3 \mathrm{~mm}$ \\
\hline \multicolumn{2}{|l|}{ Target purity } & Ni $99.9 \%$ \\
\hline \multicolumn{2}{|l|}{ Residual pressure } & $<110^{-5} \mathrm{~Pa}$ \\
\hline \multicolumn{2}{|l|}{ Temperature } & $\begin{array}{c}\text { Room } \\
\text { temperature }\end{array}$ \\
\hline \multirow{3}{*}{ HiPIMS alimentation } & Frequency & $1 \mathrm{kHz}$ \\
\hline & Pulse width & $30 \mu \mathrm{s}$ \\
\hline & Power supply & $300 \mathrm{~W}$ \\
\hline \multicolumn{2}{|l|}{ Bias voltage for step 1} & $-600 \mathrm{~V}$ \\
\hline \multicolumn{2}{|c|}{ Bias voltage for steps 2 and 3} & $-50 \mathrm{~V}$ \\
\hline \multicolumn{2}{|l|}{ Argon flow } & $10 \mathrm{sccm}$ \\
\hline \multicolumn{2}{|l|}{ Oxygen flow for step 3} & $5 \mathrm{sccm}$ \\
\hline
\end{tabular}




\begin{tabular}{|l|l|}
\hline Working pressure for steps 1 and 2 & $0.4 \mathrm{~Pa}$ \\
\hline Working pressure for step3 & $0.6 \mathrm{~Pa}$ \\
\hline
\end{tabular}

Thin films were grown in a PVD system with HiPIMS (High Power Impulsed Magnetron Sputtering) power supply. All these protocols have been described elsewhere $[4,15]$. The process includes three steps, which lead to the following stacking: Substrate/nickel/nickel/nickel oxide. The first sputtering step improves the adhesion between the substrate and coatings. Applying a high bias voltage to the substrate creates an interface mixing thanks to ionic implantation. This step also decreases the amount of surface defects by ionic peening. During the second step, a dense nickel layer [16] is deposited to minimize the oxidation of iron by preventing the diffusion of corrosive species. The last nickel oxide layer is an electronic insulating barrier [17]. The nickel oxide was obtained with an oxygen flow rate of $5 \mathrm{sccm}$ that increased the working pressure from $0.4 \mathrm{~Pa}$ to $0.6 \mathrm{~Pa}$. The coating was maintained at room temperature for at least one hour before characterization. All the deposition parameters are summarized in Table 1.

\subsubsection{Siloxane Surface Treatment}

The surface treatment used is a hybrid organic-inorganic gel deposited before painting. Condensation reaction between hydroxyl groups present on the surface of the metal and hydrolyzed precursors creates covalent bonds between the substrate and the gel that promotes adhesion. The organic part of the gel reacts with paint primer to form chemical bonds that increases adhesion between gel and paint.

Glycidyl 3- (trimethoxysilyl) propyl ether (GLYMO), zirconium (IV) tetra-1-propoxide (ZrTPO) were stirred in hydroalcoholic solution for one hour to create the sol. This solution 
1 was sprayed to the surface and dried in laboratory conditions (temperature of $22^{\circ} \mathrm{C}$ and relative

2 humidity of 50\%) as described previously [14].

During the sol drying, as well as during PVD process, stress is appearing. Without control,

4 it could lead to defects or failures in the coating. This would be disastrous for the anti-corrosive application. To this end, stress evolution was monitored. Thus, substrate curvatures were measured and an analytical model presented in the next session was applied.

7

\subsection{Stress characterization}

\subsubsection{Introduction}

Fig. 1. Flow chart linking the measurement of curvature with the analytical method of calculating the residual stress, with $K_{\text {exp }}$ : experimental curvature (green dotted box) and $K_{m o d}$ : analytical model curvature (orange dotted box).

The thermomechanical model introduced by Zhang et al. [13] calculates the residual stress associated with the application of a temperature difference on systems composed by a thin substrate and multilayered coating. Due to the different material parameters, this temperature difference causes a curvature of the sample linked to the creation of thermal residual stress.

In this study, coatings were deposited at room temperature. Thermal stress is considered to be negligible. The curvatures measured experimentally are therefore associated only with the growth process. 
Thus, as a refinement of Zhang's model, a fictive (numerical) temperature difference was adjusted in the model to reproduce the experimental curvature (Fig. 1). Then the residual stress was calculated in each layer thanks to the analytical model detailed in the following part. This one requires the material parameters and the experimental curvature as input data and allows the numerical temperature difference as variables to be fitted. Intermediately the experimental curvature, $K_{\exp }$ is fitted to the analytical model curvature, $K_{m o d}$ by least-square minimization.

\subsubsection{Analytical Model}

When a temperature difference is applied, substrate and coating are strained. The thermal strain $\alpha_{s} \Delta T$ and $\alpha_{i} \Delta T$ appear in the substrate (noted with a $s$ index) and in the layers (noted with an $i$ index) of the coating which is composed of $n$ layers. To satisfy the conditions of continuity at the interfaces, thermal stress field is generated, which induces the curvature of the coating/substrate system. The relationships between strain and stress can be expressed using Hooke's law and the balance of forces and moments, as explained elsewhere [13].

Finally, the residual stress can be expressed by equation (2) for the layers $i$ and for the substrate $s$. The term $K_{\bmod }(z+\delta)$ corresponds to the strain due to the induced bending $\varepsilon\left(K_{\bmod }\right)$. To calculate this strain the position of the neutral axis $\delta$ must be determined according to equation (3). The strain due to thermal expansion $\varepsilon^{T}$ are detailed in equations (4) and (5). The sample curvature $K_{m o d}$ is obtained using equation (6).

$$
\sigma_{i, s}(z)=E_{i, s}\left(\varepsilon_{i, s}^{T}+K_{m o d}(z+\delta)\right)
$$

$$
\delta=\frac{E_{s} t_{s}^{2}-\sum_{i=1}^{n} E_{i} t_{i}\left(2 h_{i-1}+t_{i}\right)}{2\left(E_{s} t_{s}+\sum_{i=1}^{n} E_{i} t_{i}\right)}
$$




$$
\varepsilon_{i}^{t}=\frac{E_{s} t_{s} \Delta \alpha_{i} \Delta T+\sum_{k=1}^{n} E_{k} t_{k}\left(\alpha_{k}-\alpha_{i}\right) \Delta T}{\sum_{i=1}^{n} E_{i} t_{i}+E_{s} t_{s}} \operatorname{avec}(1 \leq i \leq n, 1 \leq k \leq n)
$$

1

2

$$
\varepsilon_{s}^{t}=-\frac{\sum_{i=1}^{n} E_{i} t_{i} \Delta \alpha \Delta T}{\sum_{i=1}^{n} E_{i} t_{i}+E_{s} t_{s}}
$$

$$
K_{\text {mod }}=-\frac{\left\{3 \sum_{i=1}^{n} E_{i} t_{i}\left(2 h_{i-1}+t_{i}\right)\left[E_{s} t_{s} \Delta \alpha_{i} \Delta T+\sum_{k=1}^{n} E_{k} t_{k}\left(\alpha_{k}-\alpha_{i}\right) \Delta T\right]+3 E_{s} t_{s} \sum_{i=1}^{n} E_{i} t_{i} t_{s} \Delta \alpha_{i} \Delta T\right\}}{\left\{2 E_{s} t_{s}\left[3 \delta^{2}-3 \delta t_{s}+t_{s}^{2}\right]+\sum_{i=1}^{n} 2 E_{i} t_{i}\left[3 h_{i-1}^{2}+3 h_{i-1} t_{i}+t_{i}^{2}+3 \delta^{2}+3 \delta\left(2 h_{i-1}+t_{i}\right)\right]\right\}\left(\sum_{i=1}^{n} E_{i} t_{i}+E_{s} t_{s}\right)}
$$

In the equations above, $K_{\text {mod }}\left(\mathrm{m}^{-1}\right)$ represents the sample curvature, $z(\mathrm{~m})$ the position in the sample relative to the interface between the substrate and the first layer, $\delta(\mathrm{m})$ the position of the neutral axis, $t(\mathrm{~m})$ the thickness of the layer, $h(\mathrm{~m})$ the distance between layer $i$ and the substrate. $\alpha\left({ }^{\circ} \mathrm{C}^{-1}\right)$ represents the coefficient of thermal expansion, $\varepsilon^{t}$ the thermal strain, $E(\mathrm{~Pa})$ the Young's modulus, $k$ the number layer (from 1 to $n$ ) and $\Delta T\left({ }^{\circ} \mathrm{C}\right)$ the adjusted numerical temperature difference.

Equations (2) to (6) are used to calculate the development of residual stress during the sol-gel transition or during the growth of the nickel and nickel oxide layers. They are calculated for different heights $z$ in the substrate and in each layer(s). Depending on the thickness, the interval between two successive heights is adapted in order to keep a number of calculation points equal to 50 .

\subsubsection{Materials Parameters}

The nickel and nickel oxide coating thickness were determined by profilometry on a control sample with a contact Dektak 8 Bruker profilometer. The gel thickness was measured after drying by analyzing the sample section using a Zeiss EVO 40 Scanning Electron Microscope operating at $20 \mathrm{kV}$. From this final thickness, the variation during the sol-gel transition was calculated from gravimetric monitoring given that the relationship between mass 
1 and volume variation is proportional. This hypothesis is consistent with the observations of

2 Brinker and Scherer carried out on sols in acidic catalysis [18].

The elastic modules were measured by tensile tests for the steel thin sheet and by nanoindentation (Fischerscope ${ }^{\circledR}$ HM2000 nanoindenter) for all the materials using Oliver and Pharr method [19]. The Poisson coefficients as well as the thermal expansion coefficients were extracted from the literature [20-24]. The measured parameters are consistent with those of various literature publications. In particular, Dominguez-Rodriguez and Castaing [20] reported a modulus of elasticity for single crystals of nickel oxide identical to the present ones $(31.2$ GPa). Furthermore, the elastic modulus of steel measured by uniaxial tensile test is identical to that measured by micro-indentation $(182 \mathrm{GPa})$. All the used parameters are summarized in Table 2 and were considered to be constant during the process in a first approximation.

Table 2 : Material parameters for substrate and for each layer. ${ }^{(*)}$ Commonly used values.

\begin{tabular}{|c|l|l|c|c|c|c|}
\hline \multicolumn{2}{|l|}{} & Steel & Ni & NiO & Sol-gel \\
\hline Elastic modules & E & {$[\mathrm{GPa}]$} & 182 & 33.5 & 31.2 & 4.7 \\
\hline Poisson Coefficients & $v$ & {$[-]$} & $0,3^{(*)}$ & $0,3[21]$ & $0,3[21]$ & $0.5[22]$ \\
\hline $\begin{array}{c}\text { Thermal expansion } \\
\text { coefficients }\end{array}$ & $\alpha$ & {$\left[{ }^{\circ} \mathrm{C}^{-1}\right]$} & $1.110^{\left.-5 *^{*}\right)}$ & $\begin{array}{c}1.310^{-} \\
5[24]\end{array}$ & $\begin{array}{c}1.710^{-} \\
{ }^{5}[21]\end{array}$ & $\begin{array}{c}1.110^{-} \\
{ }^{4}[23]\end{array}$ \\
\hline
\end{tabular}

\subsection{Experimental setups}

\subsubsection{PVD process characterization}

The study focused on both the origin of the residual stress as well as on the relationship they have with the polycrystalline microstructure of the film. In order to track the evolution of the residual stress of the coating during deposition, 11 different samples were deposited for durations ranging from 5 to $60 \mathrm{~min}$. The curvature of the 11 samples was determined by image processing of the cross section using ImageJ software [25]. The trace of the cross-section is 
2 of $(x, y)$ data denoted sample displacement field. These data were plotted and they are then fitted using a second-degree polynomial. The curvature of the cross-section, $K_{\text {exp }}$, is calculated thanks

$$
K_{\text {exp }}=\frac{\left|y^{\prime \prime}\right|}{\left|\left(1+y^{\prime 2}\right)^{3 / 2}\right|}
$$

recovered in an $x, y$ frame (with $x$ and $y$ representing vertical and horizontal positions) as a set to the equation (7). Where $y$ ' and $y$ "' are the first and second derivatives of $y$, respectively.

(1)

6

Finally, the analytical model curvature $K_{\bmod }$, described in equation (6), is adjusted to match

the experimental curvature $K_{\text {exp }}$, by least-square minimization with the numerical temperature difference, $\Delta T$, as variable. The average stress level was calculated from the overall curvature generated by the deposit and the material parameters of the different layers, as input data. The incremental stress was also calculated according to the equation used by Abadias [26] to follow the instant evolution of stress. This incremental stress is representative of the change due to the last deposition layer produced or to the relaxation of the underlying film. The relationship between average stress $\bar{\sigma}$ and in-plane stress at height $z$ from the substrate $\sigma_{x x}(z)$ is given by the equation (8), with $t_{f}$ the coating thickness.

$$
\bar{\sigma}=\frac{1}{t_{f}} \int_{0}^{t_{f}} \sigma_{x x}(z) d z
$$

The stress evolution as a function of time is calculated from equation (9). The first term corresponds to the addition of a new layer with a stress of $\sigma_{\mathrm{xx}}\left(t_{f}\right)$. The second part of the equation is linked to a change in the film already deposited (stress relaxation for example). By assuming that the stress of the deposited layer does not change with time, this term can be disregarded. 


$$
\frac{\overline{d \bar{\sigma} t_{f}}}{d t}=\sigma_{x x}(h) \frac{d t_{f}}{d t}+\int_{0}^{t_{f}} \frac{\partial \sigma_{x x}(z)}{\partial t} d z
$$

The incremental stress is then calculated by deriving, with respect to the deposit thickness, the product of the average stress and the deposit thickness (product called stress $\times$ thickness) (equation (10)). The stress $\times$ thickness evolution is often presented in the literature as a function of the coating thickness. In case the stress $\times$ thickness is linearly dependent upon the coating thickness, this type of graph enables the extraction of the incremental stress which is equal to the slope of the plot.

$$
\sigma_{x x}\left(t_{f}\right)=\frac{d\left(\bar{\sigma} t_{f}\right)}{d t_{f}}
$$

In this study, the stress $\times$ thickness product is only calculated for PVD coating. In fact, for the sol-gel process stress is not linked to a growth mechanism but to drying-crosslinking reactions.

\subsubsection{Sol-Gel Process Characterization}

Equations (2) to (6) were used to calculate the development of residual stress during the sol-gel transition. One end of the sample was fixed vertically to a support, to allow the substrate to bend. A cross-sectional view of the thin steel sheet was recorded prior to the deposition, in order to assess the initial substrate curvature. Then, the sol was applied and a cross-sectional view was imaged every 15 seconds, throughout the sol drying process (about 1 hour). Finally, the evolution of the stress during drying was assessed following image processing. 


\section{Results and Discussion :}

\section{3.1 PVD Process Monitoring}

\section{3 \\ 3.1.1 Average stress and microstructure evolution}

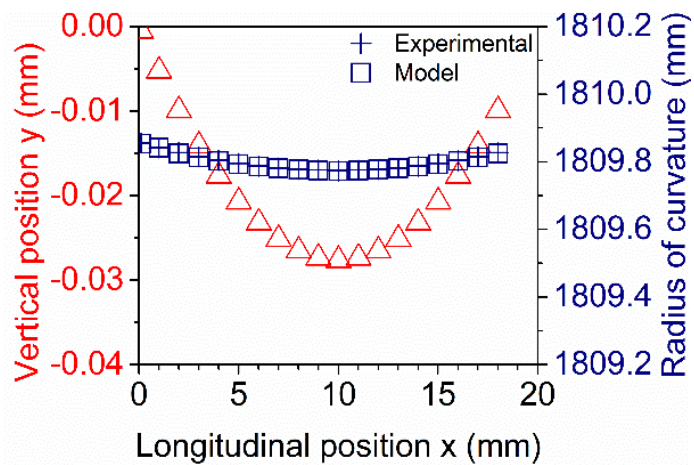

Fig. 2. Example of experimental displacement field (triangles) representing the cross section of the sample after 5 min of deposition. Corresponding experimental radius of curvature (cross) in comparison with the model (square).

Figure 2 shows the sample displacement field after 5 min of PVD deposition (red triangles). By applying a numerical temperature difference of about $-3327^{\circ} \mathrm{C}$ the experimental curvature (blue squares) is identical to the experimental curvature. This temperature difference is much higher than the real temperature of the sample. For example, C. Reinhard et al. or Lin et al. $[27,28]$ have shown that the temperature does not exceed $400^{\circ} \mathrm{C}$ with a polarization of thermal stresses can thus be neglected with respect to the stresses generated by the process. equations (2) to (6), the average stress is determined. 


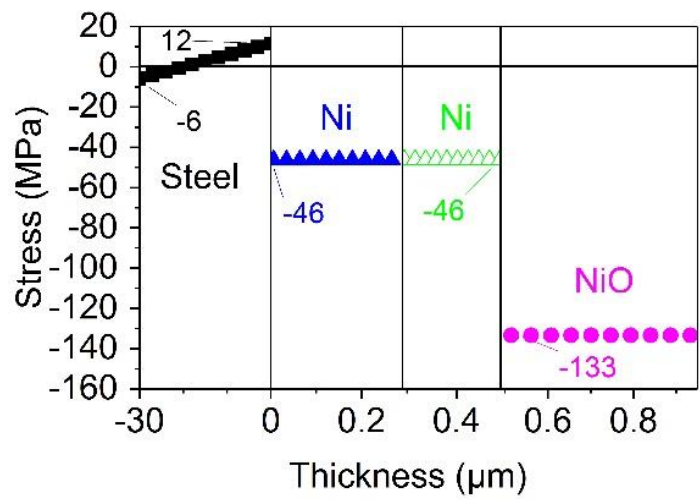

Fig. 3. Average stress level in each layer of the sample after PVD process, black squares: steel substrate, blue triangles: first step of nickel deposition, green triangle: second step of nickel deposition, pink circles: third step of nickel oxide deposition.

Fig. 3 shows the level of residual stress in the entire sample for a deposition time of 60 min corresponding to a thickness of approximately $1 \mu \mathrm{m}$. Overall, this calculated stress in the coating is relatively low. Hence, no cracking or peeling was observed. They do not exceed $133 \mathrm{MPa}$ in compression in the nickel layer deposited in steps 1 and 2 and $12 \mathrm{MPa}$ in tension in the substrate. In case of a nickel layer being peeled off from its substrate, Zhuk et al. [29] measured a residual stress of around $2 \mathrm{GPa}$. Additionally, compressive stress exceeding the order of GPa for flawless nickel oxide films have already been measured [30]. Subsequently, the stress calculated in the substrate has been disregarded since it remains much lower than the stress measured in the layers of nickel and nickel oxide. The maximum value measured does not exceed $14 \mathrm{MPa}$ in the steel when it reaches values close to $500 \mathrm{MPa}$ during the deposition of the nickel layer, as can be seen in Fig. 4.

In order to validate our analytical method, the average stress in the overall coating $(\mathrm{Ni}$ $+\mathrm{NiO}$ ) was calculated and compared to the value obtained using the Stoney equation. The analytical model has been therefore extended from a plane deformation state for the stripshaped geometry of our samples, to a plane stress state closer to the conditions necessary for the use of the Stoney equation (substrate deformation according to Kirshhoff's plate theory). Thus, the elastic modulus has been multiplied by the ratio $1 /(1-v)$ in equations (2) to (6), as mentioned by Zhang et al. [13]. By doing so, the average stress reaches: $-66.2 \mathrm{MPa}$ in the nickel 
1 layer and -190.4 MPa in the nickel oxide layer. The average of the stress in the entire coating

2 was then calculated according to equation (11) from the thicknesses: of the nickel layer $t_{N i}$, of

3 the nickel oxide layer $t_{N i O}$ and of the average stress: in the nickel layer $\sigma_{N i}$ and in the nickel

4 oxide layer $\sigma_{\mathrm{NiO}}$.

5

6

$$
\bar{\sigma}_{\text {coating }}=\frac{\bar{\sigma}_{N i} \times t_{N i}+\bar{\sigma}_{N i O} \times t_{N i O}}{t_{N i}+t_{N i o}}
$$

7 9

The use of this formula is justified because the calculated stress is homogeneous within each layer (Fig. 3). The stress thus calculated is approximately 125.6 MPa, versus $125.8 \mathrm{MPa}$ using the Stoney equation. There is therefore a good correlation between these two models, which validates our analytical method. The latter has the advantage to give access to the stress level in each layer as well as allowing us to better take into account the strip shape of our sample by considering a state of plane deformation. All the results are therefore presented considering a plane strain state.

16

17

\footnotetext{
Fig. 4. Thickness and stress level evolution during PVD process, red: positive stress (tensile stress), blue: negative stress (compressive stress).
}

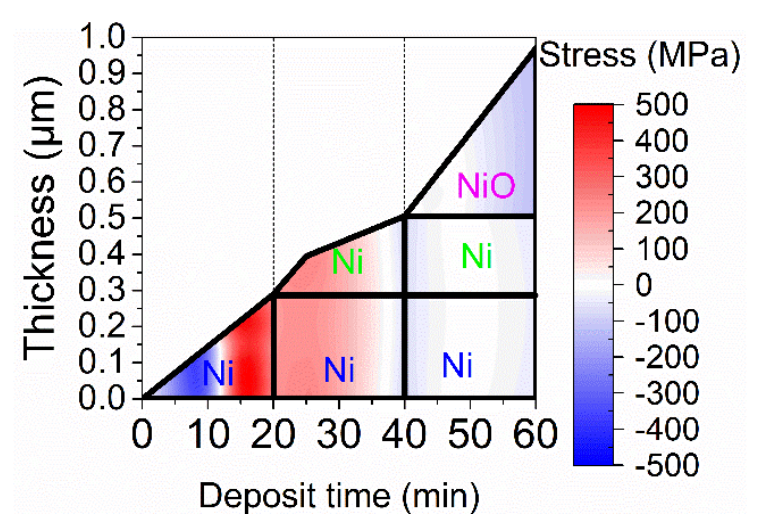

Fig. 4 shows the stress level in the different layers of the coating as a function of the deposition time. It is plotted from the stress calculated for the 11 samples by considering a 
1 linear evolution of the stress between two adjacent measurement points. As a reminder, for the

2 whole process (lasting $1 \mathrm{~h}$ ), each deposition step lasts $20 \mathrm{~min}$. The first layer of deposited nickel measures approximately $290 \mathrm{~nm}$, the second layer of nickel approximately $220 \mathrm{~nm}$ and the last layer of nickel oxide approximately $470 \mathrm{~nm}$. The final coating has a thickness close to $1 \mu \mathrm{m}$.

During growth, the stress changes greatly. Initially in compression (see Fig. 3 blue color top left-hand-side), the film goes through a tensile state (red color middle) before returning to a compression state. This behavior is conventionally encountered for thin metallic films prepared under energetic conditions [26,31-36]. It can be linked to the microstructural evolution of the coating.

Initially the film is in compression, due to the formation of independent islands on the substrate surface. The stress increases (in absolute value) as these islands grow, due to surface forces similar to the Laplace pressure as explained by Cammarata et al. [31] or Magnfält [32]. The curved surfaces cause a pressure difference between the inside and the outside of the material, which depends on the surface tension of the material and the curvature of the islands. These crystallites would therefore have a smaller lattice parameter than the bulk. However, they are fixed to the substrate when they grow, the lattice parameter cannot change to reach the value of the bulk. As the deformation is counteracted, a compressive stress appears in the coating. The more the size of the island increases, the more the stress increases before reaching a maximum and going into a traction state after $12 \mathrm{~min}$.

The transition from a compressive to a tensile stress state is almost instantaneous. This phenomenon is conventionally explained by the formation of grain boundaries between islands, when the latter are close enough to exert on each other a force of attraction. This phenomenon was described as a "zipping process" by Hoffman [37]. Thus, the adjacent islands would come in contact to form a new grain boundary, as long as the increase in the deformation energy is less than the decrease in the interfacial energy. The compression deformation caused by the 
1 joint would cause tension stress to appear in the coating due to the adhesion forces of the coating

2 on the substrate. This phenomenon occurs in our study when the nickel crystallites reach a size

3 of approximately $130 \mathrm{~nm}$ after approximately $12 \mathrm{~min}$. In the literature, no critical value associated to this phenomenon could be found for a Ni coating deposited by HiPIMS on a steel substrate. However, crystallite sizes ranging from a few tens of nanometers $[32,33]$ to a few micrometers in case of electrodeposited $\mathrm{Ni}$ coating [38], are reported to trigger the transition from compression to tension. Chason et al. obtained a crystallite size of around $10 \mu \mathrm{m}$ thanks to a silicon-based substrate made up of three layers ( $\mathrm{Ti}, \mathrm{Au}$ and photoresist layer). Therefore, with a critical value of $\sim 130 \mathrm{~nm}$, our results for this type of material are consistent with the literature.

After 12 min of deposition, the stress decrease during the rest of the process (end of step 1, step 2 and step 3) to return to a state of traction after approximately $35 \mathrm{~min}$. This reduction in the observed stress can be attributed to the energetic deposition mode (HiPIMS power supply) which causes the appearance of incremental stress in compression. The origin of these has been the subject of numerous studies $[34,39,40]$. Overall, they are associated with a densification of the material linked to an atomic peening phenomenon. Following a succession of atom collisions in the coating called "knock-on mechanisms," atoms are inserted at the grain boundaries, which causes the material to expand. However, the lateral dimensions of the film are fixed by those of the substrate. As the layer is not free, compression stress appears in the film.

Therefore, by monitoring the average stress, it is possible to plot the evolution of the microstructure during deposition. The results obtained are in agreement with the literature. Initially in compression, the stress evolves through a tensile state following the creation of grain boundaries for crystallite sizes of around $130 \mathrm{~nm}$. Then, the average stress decreases following 
1 the incorporation of atoms at these grain boundaries, which causes incremental compressive

2 stress. In order to assess the level of this stress, Fig. 5 has been plotted.

3

\subsubsection{Stress $\times$ thickness evolution}

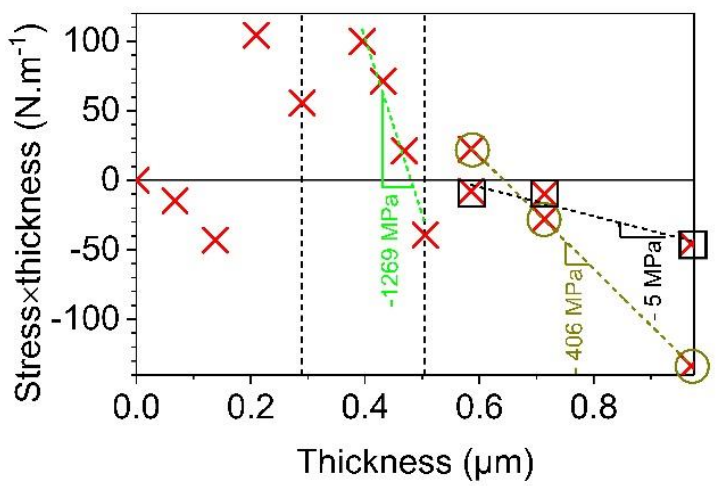

Fig. 5. Stress $\times$ thickness evolution versus coating thickness, incremental stress corresponding to the slope of the trace, green dotted line: nickel layer (second step), brown dotted line with brown circle: nickel oxide layer (third step), black dotted line with black squares: nickel layer.

Fig. 5 shows the stress $\times$ thickness evolution as a function of the coating thickness.

Discontinuities are visible between each stage. These are represented by dotted vertical lines.

They can be explained by the relaxation of the incremental stress when the process is interrupted. Indeed, between step 1 and step 2, on the one hand, and step 2 and step 3, on the other hand, a shutter is placed between the source and the sample. During this operation the new plasma parameters are adjusted so that the plasma is at steady state before restarting the deposition. During this time, part of the atoms inserted at the grain boundaries have time to diffuse towards the surface. These atoms are responsible for the incremental stress in compression. So, from one step to the following one, when atoms diffuse towards the outside of the boundaries, as already reported and explained in the literature [26,35,41-44], the associated relaxation phenomenon induces an increase in the average stress. 
During step 1, the process is not in a steady state. The coating is not continuous and the

2 evolution of the stress $\times$ thickness product with time is not linear, therefore the incremental stress cannot be extracted. During steps 2 and 3, the evolution of the product is linear with the thickness, which allows us to calculate the incremental stress linked to the deposition of the layers of nickel and nickel oxide.

This stress reaches approximately -1.3 GPa for the deposition of nickel, during step 2 of the process. For electro-deposited nickel Hearn and Floro [45] found, by varying their deposit conditions, incremental stress ranging from $131 \mathrm{MPa}$ to -50 MPa. Furthermore, Hoffman and Thornton [46] found a value of 0.3 GPa for nickel deposited by PVD magnetron. Finally, Magnfält et al.[47] obtained for Mo coatings deposited in HiPIMS stress up to 2 GPa. The value of -1.3 GPa calculated in our study therefore seems consistent with regard to the literature.

The incremental stress reaches approximately - $406 \mathrm{MPa}$ for the nickel oxide layer. This generates an incremental stress of - $5 \mathrm{MPa}$ in the underlying nickel layer. For the nickel oxide deposition, Keraudy et al. [30] found a positive incremental stress. Indeed, in their study, when the coating thickness increases the average residual stress becomes less compressive. This result is not in agreement with Fig. 5. However, their study was carried out on a different substrate, without substrate polarization and in Direct Current (DC). Actually, HiPIMS mode involves the presence of energetic species in the plasma that creates a denser layer than in DC [17]. These species might lead to the development of incremental compressive stress. No study has been found on the influence of one layer deposition on a previous one. Therefore, the present analytical method advantageously enables us to decompose the average stress in the form of contribution linked to the deposition of each layer.

All the results seem to be consistent with regard to the literature as well as provide experimental data on the deposition of multilayer coating in HiPIMS mode. The phenomena 
1 involved, conventionally observed during the growth of a PVD deposit, explain the low level

2 of average stress at the end of the process. They would be linked to the superposition of tensile

3 stress and compressive stress leading to a flawless coating. This result is critical for the

4 anticorrosive application since damages in this multilayer surface treatment would lead to paint

5 debonding and/or failure. So the analytical model is adapted to the characterization of metallic

6 thin film formation, it is also adapted to the characterization of a chemical process, such as sol-

7 gel route, as shown in the following section.

8 


\subsection{Sol-Gel Process Monitoring}

2 3

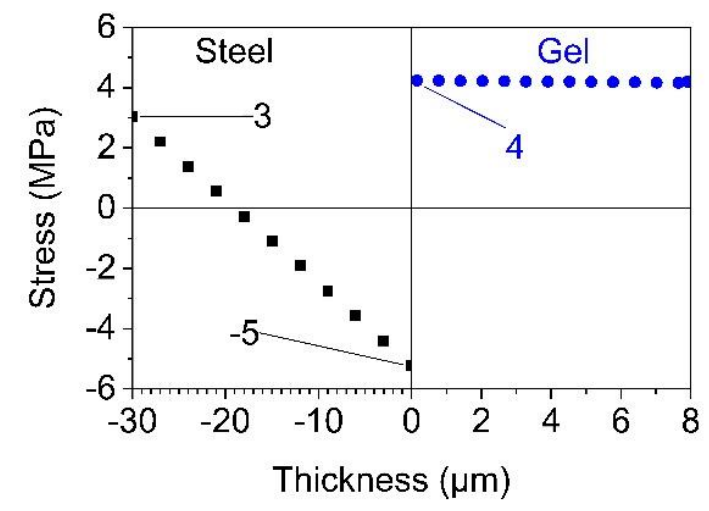

Fig. 6. Stress levels in the substrate and in the gel after sol-gel process (60 min of drying time), black square: steel substrate, blue circles: gel.

Fig. 6 is an example of the result obtained during monitoring of a sol drying, here for 60 minutes. The stress calculated in the coating is relatively low, since it ranges from $3 \mathrm{MPa}$ to $5 \mathrm{MPa}$. It is homogeneous in the coating thickness and reaches approximately $4 \mathrm{MPa}$. In the same way as for the PVD process, the average stress calculated from the Stoney equation and from the analytical model by considering a state of plane strain are equivalent (around $5 \mathrm{MPa}$ ). The analytical model proposed herein is therefore also suitable for the characterization of coating deposited by a chemical process.

The adhesion between the coating and the substrate can be evaluated by the stress difference at the interface $\Delta \sigma\left(\Delta \sigma=\sigma_{\text {coating }}-\sigma_{\text {substrat }}\right)$. This stress difference is around $9 \mathrm{MPa}$, which seems relatively low and explains the good adhesion of the coating. Thereafter the average stress of the coating was plotted as a function of the drying time and the thickness, Fig. 7 (a). 

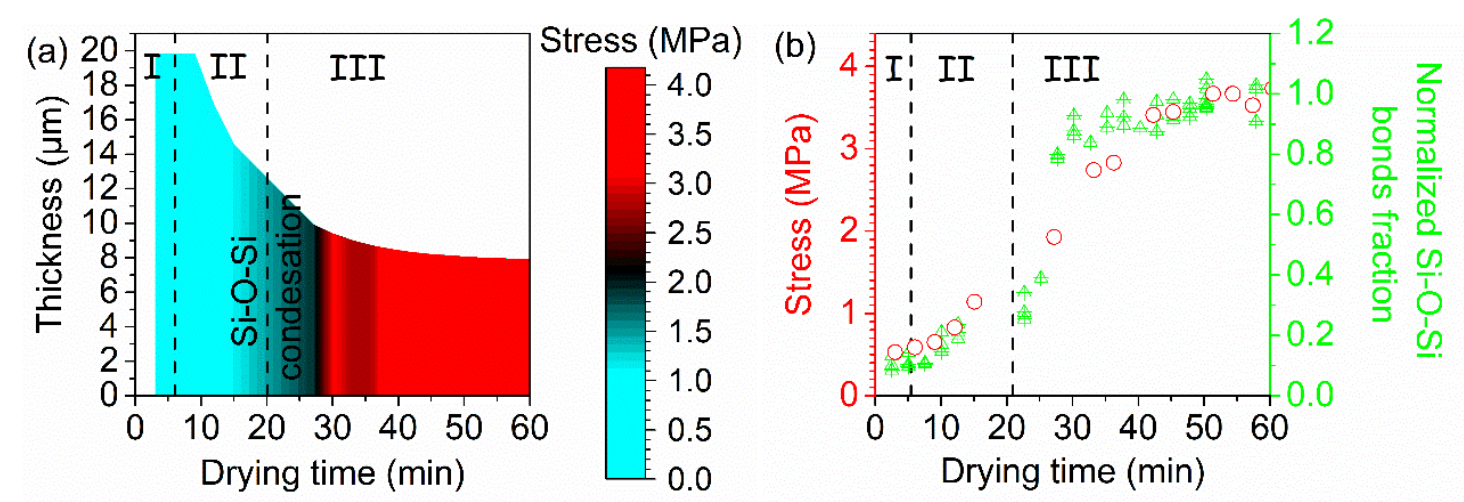

Fig. 7. Coating parameter evolutions during drying: (a) thickness and stress level evolution, (b) stress and normalized Si-O-Si bonds fraction evolution according to Hatte et al. [14].

4

This figure depicts the evolution of the stress calculated from the analytical model, as a function of the time after sol deposition and coating thickness. Initially, the sol is in a liquid state, the sample curvature is close to infinity, so the stress is very low. After 20 min the stress increases very quickly, before stabilizing at a value close to $4 \mathrm{MPa}$ after $36 \mathrm{~min}$. The gel gets its final thickness and the stress is stable after $60 \mathrm{~min}$. The sudden change observed after $20 \mathrm{~min}$ is due to the transition from the liquid state to the gel state. In this case, the sol-gel transition would therefore lie between 20 and $36 \mathrm{~min}$. This value is consistent with the time found in our previous study [14] via the Dynamic Vapor Sorption test (i.e. $30 \mathrm{~min}$ at $22^{\circ} \mathrm{C}$ and $50 \%$ relative humidity).

Fig. 7 (b) shows the evolution of the normalized Si-O-Si bonds fraction and coating stress after sol deposition. The infrared band at $1100 \mathrm{~cm}^{-1}$ was integrated and divided by the total integrated intensity of the spectrum as explained and detailed in our previous work. The three stages of the drying process identified have been superimposed in Fig. 7 (a) and (b).

During stage I, the stress is very low, which is consistent with a sol in the liquid state and a loss of mass linked to the evaporation of the solvents. The normalized intensity of Si-OSi bonds observed by infrared spectrometry during the previous study is low, which implies that the inorganic network is not yet formed. 
Then, during stage II, drying occurs by evaporation of solvent(s) through a porous medium. During this stage the stress begins to develop slowly following the start of the formation of the inorganic network. At the same time, a slow increase in the normalized intensity of Si-O-Si bonds was observed. After 18 minutes, the increase in stress accelerates. This is correlated with the sudden increase in the normalized intensity of Si-O-Si bonds attributed to the formation of the inorganic network. The stress comes therefore mainly from a chemical origin and is linked to the condensation reactions in the gel.

During stage III, after 30 minutes, the stress is relatively stable, as is the normalized intensity of the Si-O-Si bonds. The network is therefore already constituted, but the thickness of the coating continues to decrease. These results indicate a drying of the solvents in vapor phase through the network.

From Fig. 7 (a) we infer that the gel formation occurs before the coating has completely dried. This is a mechanism called ("gel-before-dry phenomenon") in the literature [5]. The solvents were removed slowly enough for the condensation and crosslinking reactions to occur before drying (stage II). The coating obtained in this way is more condensed and isotropic, as explained by Cairncross et al. [5]. It is thus more rigid and thicker, since part of the solvents is encapsulated in the coating during crosslinking.

This study therefore highlights the drying mechanism. This is dependent on ambient conditions of temperature and relative humidity, as highlighted by X-Ray photoelectron spectrometry measurements [14]. In laboratory conditions $\left(22^{\circ} \mathrm{C}\right.$ and $50 \%$ relative humidity), drying lasts 36 minutes leading to a low stressed gel suitable for anticorrosive applications. Depending on the intended application, temperature and relative humidity could be chosen in order to obtain a more or less condensed and therefore more or less stressed coating. This analytical method of process monitoring by stress measurements therefore provides an 
1 understanding of the mechanisms involved during the sol-gel transition. This information can

2 be used to develop this solution for the intended application. 


\section{Conclusion}

2

In the present study, the evolution of residual stress linked to the PVD and sol-gel processes was investigated thanks to a versatile analytical method. This is based on an optical measurement of the curvature of films growing on thin substrates. Then this experimental data together with the material mechanical parameters are introduced as input data in an analytical model allowing to extract the residual stress. In addition to the average residual stress in the coating, and more importantly the stress in each layer for multi-layer coatings are also accessible. In the case of PVD deposition, the proposed methodology allows us to assess the level of the incremental stress related to the last layer deposited. All the results were validated by comparing them to values calculated from Stoney's equation and the literature.

The study also provides results regarding the level of residual stress in sol-gel and PVD deposited films, highlighting the versatility of the analytical method used. For the PVD coating, it was possible to relate the development of the stress to the evolution of the film structure during growth. For the sol-gel process, the study of the stress allowed highlighting the mechanisms involved during the sol-gel transition and their influence on the gel structure. Both surface treatments have a low level of residual stress, which explains why they are flawless and which is interesting for the targeted anti-corrosion application.

Finally, this analytical method could be used in the future as a development tool to monitor the stress at interfaces and hence further optimize the process to limit the formation of defects in coatings and interlayers. 
3 Acknowledgements: This work is part of the French Optisurf project, funded by the IRT

4 Jules Verne (Bouguenais, France). We would like to thank their industrial (General Electric,

5 Socomore) and academic partners (Nantes University, CNRS).

6 This research did not receive any specific grant from funding agencies in the public, 7 commercial, or not-for-profit sectors.

8 


\section{References}

[1] J.A. Thornton, D.W. Hoffman, Stress-related effects in thin films, Thin Solid Films. 171 (1989) 5-31. https://doi.org/10.1016/0040-6090(89)90030-8.

[2] R. Boijoux, G. Parry, J.-Y. Faou, C. Coupeau, How soft substrates affect the buckling delamination of thin films through crack front sink-in, Appl. Phys. Lett. 110 (2017) 141602. https://doi.org/10.1063/1.4979614.

[3] M. George, C. Coupeau, J. Colin, J. Grilhé, Mechanical behaviour of metallic thin films on polymeric substrates and the effect of ion beam assistance on crack propagation, Acta Mater. 53 (2005) 411-417. https://doi.org/10.1016/j.actamat.2004.09.036.

[4] P.A. Dubos, Q. Hatte, P. Casari, M. Richard-Plouet, P.-Y. Jouan, S. Branchu, N. Guitter, Stress Gradient Determination in Anti-Corrosion Multilayer Coating, Mater. Sci. Forum. (2018). https://doi.org/10.4028/www.scientific.net/MSF.941.1632.

[5] R.A. Cairncross, L.F. Francis, L.E. Scriven, Predicting Drying in Coatings that React and Gel: Drying Regime Maps, AIChE J. 42 (1996) 55-67. https://doi.org/10.1002/aic.690420107.

[6] J.A. Thornton, The microstructure of sputter- deposited coatings, J. Vac. Sci. Technol. A. 4 (1986) 3059-3065. https://doi.org/10.1116/1.573628.

[7] D. Gloaguen, M. François, R. Guillen, Mesoscopic residual stresses of plastic origin in zirconium: interpretation of X-ray diffraction results, J. Appl. Crystallogr. 37 (2004) 934-940. https://doi.org/10.1107/S0021889804022034.

[8] G.G. Stoney, C.A. Parsons, The tension of metallic films deposited by electrolysis, Proc. R. Soc. Lond. Ser. Contain. Pap. Math. Phys. Character. 82 (1909) 172-175. https://doi.org/10.1098/rspa.1909.0021.

[9] M.A. Djouadi, V. Mortet, S. Khandozhko, P.Y. Jouan, G. Nouet, Dynamic stress investigations for cubic boron nitride films deposited by triode sputtering technique, Surf. Coat. Technol. 142144 (2001) 899-905. https://doi.org/10.1016/S0257-8972(01)01123-9.

[10] S. Dreier, B. Denkena, Determination of Residual Stresses in Plate Material by Layer Removal with Machine-integrated Measurement, Procedia CIRP. 24 (2014) 103-107. https://doi.org/10.1016/j.procir.2014.07.137.

[11] D. Gloaguen, J. Fajoui, B. Girault, Residual stress fields analysis in rolled Zircaloy-4 plates: Grazing incidence diffraction and elastoplastic self-consistent model, Acta Mater. 71 (2014) 136-144. https://doi.org/10.1016/j.actamat.2014.02.031.

[12] T.-Y. Zhang, L.-Q. Chen, R. Fu, Measurements of residual stresses in thin films deposited on silicon wafers by indentation fracture, Acta Mater. 47 (1999) 3869-3878. https://doi.org/10.1016/S1359-6454(99)00248-7.

[13] X.C. Zhang, B.S. Xu, H.D. Wang, Y.X. Wu, An analytical model for predicting thermal residual stresses in multilayer coating systems, Thin Solid Films. 488 (2005) 274-282. https://doi.org/10.1016/j.tsf.2005.04.027.

[14] Q. Hatte, P.-A. Dubos, N. Guitter, M. Richard-Plouet, P. Casari, Influence of relative humidity and temperature on the sol-gel transition of a siloxane surface treatment, J. Sol-Gel Sci. Technol. 90 (2019) 230-240. https://doi.org/10.1007/s10971-019-04929-0.

[15] P.-Y. Jouan, J. Keraudy, A. Ferrec, Nickel-Based Anti-Corrosion Coating and Process for Obtaining Same, WO/2017/085279, 2017. https://patentscope.wipo.int/search/en/detail.jsf?docId=WO2017085279 (accessed December 3, 2019).

[16] J. Keraudy, D.T. Nguyen, A. Ferrec, P.-Y. Jouan, Comparison Between DC and HiPIMS Discharges. Application to Nickel Thin Films, in: H. Fujita, D.C. Nguyen, N.P. Vu, T.L. Banh, H.H. Puta (Eds.), Adv. Eng. Res. Appl., Springer International Publishing, Cham, 2019: pp. 196-203. https://doi.org/10.1007/978-3-030-04792-4_27.

[17] J. Keraudy, B. Delfour-Peyrethon, A. Ferrec, J. Garcia Molleja, M. Richard-Plouet, C. Payen, J. Hamon, B. Corraze, A. Goullet, P.-Y. Jouan, Process- and optoelectronic-control of NiOx thin films deposited by reactive high power impulse magnetron sputtering, J. Appl. Phys. 121 (2017) 171916. https://doi.org/10.1063/1.4978349. 
[18] C.J. Brinker, G.W. Scherer, Sol-Gel Science: The Physics and Chemistry of Sol-Gel Processing, Academic Press, 1990.

[19] W.C. Oliver, G.M. Pharr, An improved technique for determining hardness and elastic modulus using load and displacement sensing indentation experiments, J. Mater. Res. 7 (1992) 15641583. https://doi.org/10.1557/JMR.1992.1564.

[20] A. Dominguez-Rodriguez, J. Castaing, Déformation plastique de l'oxyde de nickel monocristallin, Rev. Phys. Appliquée. 11 (1976) 387-391. https://doi.org/10.1051/rphysap:01976001103038700.

[21] C. Liu, A.-M. Huntz, J.-L. Lebrun, Origin and development of residual stresses in the $\mathrm{Ni} \square \mathrm{NiO}$ system: in-situ studies at high temperature by X-ray diffraction, Mater. Sci. Eng. A. 160 (1993) 113-126. https://doi.org/10.1016/0921-5093(93)90504-8.

[22] S. Dogru, B. Aksoy, H. Bayraktar, B.E. Alaca, Poisson's ratio of PDMS thin films, Polym. Test. 69 (2018) 375-384. https://doi.org/10.1016/j.polymertesting.2018.05.044.

[23] M. Pokrass, Z. Burshtein, R. Gvishi, Thermo-optic coefficient in some hybrid organic/inorganic fast sol-gel glasses, Opt. Mater. 32 (2010) 975-981. https://doi.org/10.1016/j.optmat.2010.01.038.

[24] N. Karimi, Etude par diffraction des rayons X in situ des mécanismes d'oxydation de l'acier AISI 304 entre $800^{\circ} \mathrm{C}$ et $1000^{\circ} \mathrm{C}$. Influence des dépôts sol-gel de lanthane et de cérium. Apport de la spectroscopie infrarouge à l'identification des oxydes mixtes, Chimie théorique et/ou physique, Université Blaise Pascal - Clermont-Ferrand II, 2007. Français.

[25] C.A. Schneider, W.S. Rasband, K.W. Eliceiri, NIH Image to ImageJ: 25 years of image analysis, Nat. Methods. 9 (2012) 671-675. https://doi.org/10.1038/nmeth.2089.

[26] G. Abadias, E. Chason, J. Keckes, M. Sebastiani, G.B. Thompson, E. Barthel, G.L. Doll, C.E. Murray, C.H. Stoessel, L. Martinu, Review Article: Stress in Thin Films and Coatings: Current Status, Challenges, and Prospects, J. Vac. Sci. Technol. Vac. Surf. Films. 36 (2018) 020801. https://doi.org/10.1116/1.5011790.

[27] C. Reinhard, A.P. Ehiasarian, P.Eh. Hovsepian, $\mathrm{CrN} / \mathrm{NbN}$ superlattice structured coatings with enhanced corrosion resistance achieved by high power impulse magnetron sputtering interface pre-treatment, Thin Solid Films. 515 (2007) 3685-3692. https://doi.org/10.1016/j.tsf.2006.11.014.

[28] T. Lin, L. Wang, X. Wang, Y. Zhang, Y. Yu, Influence of bias voltage on microstructure and phase transition properties of VO2 thin film synthesized by HiPIMS, Surf. Coat. Technol. 305 (2016) 110-115. https://doi.org/10.1016/j.surfcoat.2016.08.020.

[29] A.V. Zhuk, A.G. Evans, J.W. Hutchinson, G.M. Whitesides, The adhesion energy between polymer thin films and self-assembled monolayers, J. Mater. Res. 13 (1998) 3555-3564. https://doi.org/10.1557/JMR.1998.0484.

[30] J. Keraudy, J. García Molleja, A. Ferrec, B. Corraze, M. Richard-Plouet, A. Goullet, P.-Y. Jouan, Structural, morphological and electrical properties of nickel oxide thin films deposited by reactive sputtering, Appl. Surf. Sci. 357 (2015) 838-844. https://doi.org/10.1016/j.apsusc.2015.08.199.

[31] R.C. Cammarata, T.M. Trimble, D.J. Srolovitz, Surface stress model for intrinsic stresses in thin films, J. Mater. Res. 15 (2000) 2468-2474. https://doi.org/10.1557/JMR.2000.0354.

[32] D. Magnfält, Nucleation and Stress Generation in Thin Films Deposited with a Pulsed Energetic Deposition Flux, DIVA. (2013). http://urn.kb.se/resolve?urn=urn:nbn:se:liu:diva-86472 (accessed August 10, 2018).

[33] F. Cemin, D. Lundin, C. Furgeaud, A. Michel, G. Amiard, T. Minea, G. Abadias, Epitaxial Growth of $\mathrm{Cu}(001)$ Thin Films onto $\mathrm{Si}(001)$ using a Single-Step HiPIMS Process, Sci. Rep. 7 (2017) 1655. https://doi.org/10.1038/s41598-017-01755-8.

[34] E. Chason, M. Karlson, J.J. Colin, D. Magnfält, K. Sarakinos, G. Abadias, A Kinetic Model for Stress Generation in Thin Films Grown from Energetic Vapor Fluxes, J. Appl. Phys. 119 (2016) 145307. https://doi.org/10.1063/1.4946039.

[35] E. Chason, P.R. Guduru, Tutorial: Understanding Residual Stress in Polycrystalline Thin Films Through Real-Time Measurements and Physical Models, J. Appl. Phys. 119 (2016) 191101. https://doi.org/10.1063/1.4949263. 